\title{
Evaluation of Glutathione-S-transferase and Ceruloplasmin levels in gingival crevicular fluid and gingival tissue as diagnostic markers for chronic periodontitis
}

\author{
Jothi M. Varghese ${ }^{1 *}$, Vinutha Bhat ${ }^{2}$, G. S. Bhat ${ }^{1}$, Namita Rao ${ }^{2}$ \\ ${ }^{1}$ Department of Periodontics, Manipal College of Dental Sciences (MCODS), Manipal, India \\ ${ }^{2}$ Department of Biochemistry, KMC, Manipal University, Manipal, India \\ Email: ${ }^{*}$ jothimv@gmail.com
}

Received 10 June 2012; revised 10 July 2012; accepted 28 July 2012

\begin{abstract}
Periodontitis, is an infectious ailment of multifactorial origin, that brings about destruction of bone and surrounding tissues. There are various oral pathogens that may be responsible for the destruction. The host encounters these microbial invasions and their products by the production and release of inflammatory mediators from the cells within the body. Glutathione-S-transferase (GST) are a group of enzymes that utilize glutathione in conditions resulting in oxidative stress. These enzymes play a key role in the detoxification of such substance. It aids in preventing damage to important cellular components caused by release of free reactive oxygen species. Ceruloplasmin is a ferroxidase enzyme. It plays a role as an anti-inflammatory agent, by its ability to scavenge free radicals within the body. The present study was targeted at evaluating the levels of Glutathione-S-transferase (GST) and Ceruloplasmin as diagnostic markers for patients with chronic periodontitis in gingival crevicular fluid (GCF) and the gingival tissues. Thirty patients were divided into two groups. Experimental group comprising of 15 subjects with chronic periodontitis and the control group was composed of $\mathbf{1 5}$ healthy individuals. Highly significant changes in GST between the diseased and normal patients $(P=$ 0.001) were detected. There was a decrease in GST level in both gingival tissue \& GCF in diseased patients when compared to the control patients. The ceruloplasmin levels in GCF and gingival tissues showed no difference between the control and diseased group. Hence, these results indicate a relationship suggesting that GST produced during chronic inflammation could be used as biomarker that indicate periodontal disease.
\end{abstract}

Keywords: Glutathione-S-Transferase; Ceruloplasmin;

"Corresponding author.
GCF; Gingival Tissues; Chronic Periodontitis

\section{INTRODUCTION}

Periodontal diseases are a group of inflammatory diseases mainly caused by bacteria and their products [1] The host encounters these microbial invasions and their products by the production and release of inflammatory mediators from the cells within the body namely lymphocytes, monocytes and those of mesenchymal origin such as fibroblasts, osteoblasts. These local factors produced during periodontal disease can be found in both gingival crevicular fluid and gingival tissues. Glutathione (GSH) also known as the "Master antioxidants" is a tripeptide that is present in almost all cells of the body. It aids in preventing damage to important cellular components caused by reactive oxygen species such as free radicals and peroxides [2]. In aggressive and chronic forms of periodontitis, polymorpho nuclear leucocytes appear to be functionally activated and exhibit increased production of reactive oxygen species (ROS) [3-5]. These molecules are reported to be capable of inducing periodontal tissue destruction [6] and are associated with osteoclastic bone resorption [7]. To combat these excessive ROS production, the body possesses a variety of anti-oxidant defense mechanisms, which act concurrently. These protect the vital cells and tissues by removing them as they form or by repairing the damage caused by it [8]. A delicate balance exists between the defence and repair systems within the body, any activity that outweighs the balance infavor of the ROS activity ensues a significant tissue damage.

Glutathione-S-transferase (GST) are a family of enzymes that utilize glutathione in reactions contributing to the transformation of a wide range of compounds and products of oxidative stress. These enzymes play a key role in the detoxification of such substances. There are literary evidence linking involvement of GST in cellular 
processes of inflammation, aging and degenerative diseases [9]. Even associations with inflammatory diseases, rheumatoid arthritis and metabolic disorders have been reported [10].

Ceruloplasmin is a ferroxidase enzyme. It plays a role as an anti-inflammatory agent, thus reducing the oxidative stress by its ability to scavenge superoxide anion radicals $[11,12]$. Local inflammation is characterized by reduced oxygen content in the tissues, which in turns stimulates the expression of hypoxia inducible factor (HIF)-1a [13,14]. Ceruloplasmin is a downstream target for HIF-1a and may play a central role in excessive superoxide when exposed to local inflammation-induced hypoxia [15]. Based on above reviews linking these enzymes with inflammatory processes within the body, the aim of this study was to evaluate the levels of GST and ceruloplasmin in both the gingival crevicular fluid and gingival tissues as diagnostic markers for patients with chronic periodontitis.

\section{MATERIALS AND METHODS}

This case control study was carried out in the department of Periodontics, Manipal College of Dental Sciences, Manipal. Approval for the study was granted by the Institutional Review Board of Manipal University.

\subsection{Clinical Trial Design}

Thirty patients $\geq 30$ years of age were divided into two groups. Experimental group comprised of 15 subjects with chronic periodontitis and control group which was consisted of 15 healthy individuals with no prior history of periodontal disease with a minimum of 20 natural teeth who had generalized gingival inflammation, periodontal pockets of $\geq 5 \mathrm{~mm}$, attachment loss $\geq 5 \mathrm{~mm}$ either in the maxillary or mandibular arches, bleeding on probing were selected. Patients were excluded if they were pregnant, had systemic disease, or a history of antibiotic treatment within the past 6 months.

At the initial visit, oral prophylaxis was performed to both groups and oral hygiene instructions were advised. Patients were then recalled after two weeks for review. Only those patients with residual pocket probing depth $\geq 5 \mathrm{~mm}$ were included in the experimental group. The subjects of the experimental group were then subjected for a pocket reduction surgical procedure. The subjects who did not have any gingival inflammation were considered under the control group.

All the periodontal parameters (bleeding on probing, pocket depth and clinical attachment loss) along with GCF collection and enzymatic analysis were assessed for both groups, and performed by a periodontist (DELETE THIS LINE).

\subsection{Tissue Samples}

Experimental group: As part of pocket reduction procedure, a full thickness flap was raised, the infected granulation tissue was procured with a curette either from buccal, lingual or interproximal area. The sample was immediately placed in a transport medium, with phosphate buffer (6.5) and submitted for enzymatic analysis.

Control group: The tissue samples were obtained from patients undergoing surgical removal of third molar or tooth extraction for orthodontic purposes.

\subsection{Method of GCF Collection}

A Whatman no. 1 filter paper disc of $3 \mathrm{~mm}$ diameter was carefully introduced into the sulcus of the tooth with a tweezer and left in position for 2 minutes. At the end of two minutes, the filter paper disc was transferred into vials containing $5 \mathrm{ml}$ phosphate buffer solution, used as a transport media. Thereafter the solution was subjected for GST and Ceruloplasmin enzyme analysis using the same techniques mentioned above $[16,17]$.

\subsection{Enzymatic Analysis}

Glutathione-S-transferase: The method described by Beutler et al. [16] was employed to analyze the enzymatic activity of GST both in gingival tissue and GCF samples. The tissue samples were thawed, homogenized. The GST activity was determined at $340 \mathrm{~nm}$ at intervals of $5 \mathrm{mi}-$ nutes using CDNB (1-chloro-2,4-dinitrobenezene) as a substrate.

Ceruloplasmin: These levels were determined by the diamine oxidase method [17] based on the property of ceruloplasmin to catalyse an oxidative reaction and form a blue-violet complex which can be estimated at $532 \mathrm{~nm}$ spectrophotometrically.

The statistical analysis was performed using MannWhitney "U" test for assessment of GST levels (ADD THIS LINE) and students' " $t$ " test was used to assess the levels of ceruloplasmin. Significance was accepted for P $\leq 0.05$.

\section{RESULTS}

The present clinical study was done to evaluate the levels of GST and ceruloplasmin in healthy adults and patients with chronic periodontitis.

The statistical observations demonstrated a highly significant increase in GST levels both in GCF and tissue in control (healthy) group when compared to experimental (diseased) group (Figures 1, 2).

Intergroup comparison in the GST levels between GCF and tissue samples both in the control and experimental group did not show any significant difference, though the GST levels were slightly more in the gingival 
tissues in both groups than GCF (Figures 1, 2, Graph I) (GRAPH Not included in text, to be added).

Ceruloplasmin levels in GCF and tissue of both the control and experimental group showed no significant changes (Tables 1, 2).

\section{DISCUSSION}

The excess production or decreased clearance of ROS through the antioxidant mechanism may result in oxidative stress which is directly related to lipid peroxidation within the cells $[18,19]$. Panjamurthy et al. [20] found

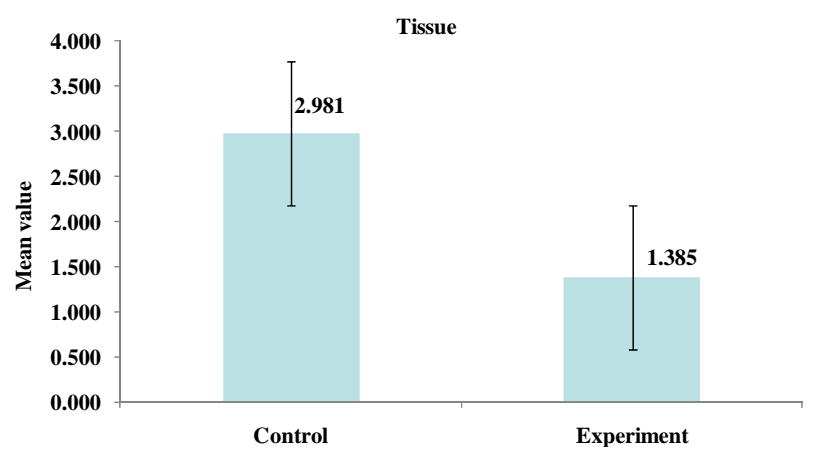

Figure 1. Comparison of mean GST levels in gingival tissues of control (healthy) and experimental (diseased) groups.

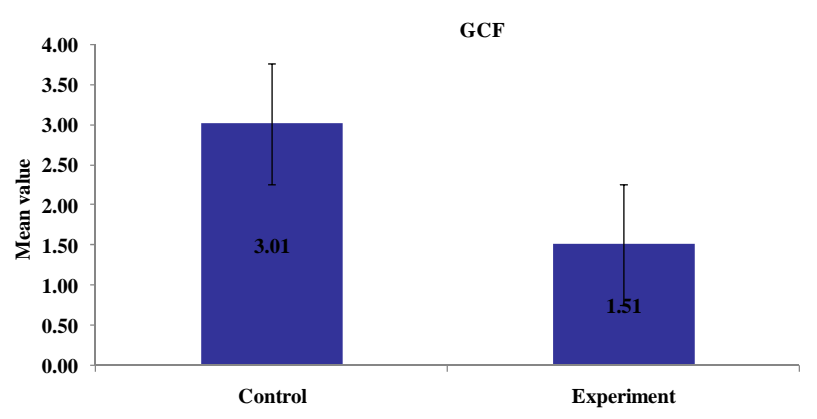

Figure 2. Comparison of mean GST levels in GCF of control (healthy) and experimental (diseased) group.

Table 1. Ceruloplasmin levels in GCF.

\begin{tabular}{|c|c|c|c|c|}
\hline GROUP & $\mathrm{N}$ & Mean & Std. Deviation & $\mathrm{t}$ \\
\hline Control & 15 & 0.113 & 0.0280 & $\begin{array}{c}1.511000 \\
\mathrm{P}=0.142 \mathrm{~ns}\end{array}$ \\
\hline Experimental & 15 & 0.252 & 0.354 & \\
\hline
\end{tabular}

"ns: not significant.

Table 2. Ceruloplasmin levels in Tissues.

\begin{tabular}{ccccc}
\hline GROUP & $\mathrm{N}$ & Mean & Std. Deviation & $\mathrm{t}$ \\
\hline Control & 15 & 0.105 & 0.0275 & $\begin{array}{c}1.511000 \\
\text { Experimental }\end{array}$ \\
\hline
\end{tabular}

"ns: not significant. that individuals with periodontitis had increase in some oxidative stress biomarkers and decrease in some antioxidants compared with healthy individuals and postulated that these changes were related to the increase in lipid peroxides and oxidative stress in periodontitis.

In this particular study, both gingival tissue and GCF was considered for analysis. GCF is the most suitable fluid to sample when examining the periodontal condition, as it flows through the tissues and accumulates within tissues. Gingival tissues from sites of periodontitis reveals a diverse population of inflammatory cells, proinflammatory cytokines etc. According to the data provided by Ellis and co-workers [21], there exists a possibility of a favorable gingival microenvironment for product of ROS by phagocytic cells and decrease antioxidant activity. In this clinical trial, the GST activity in GCF and gingival tissue was significantly higher in the control group when compared to the experimental group where the levels were considerably reduced. The high concentration of glutathione present in GCF in health are similar to those found extracellularly in the lung and may represent an important antioxidant and anti-inflammatory defence strategy common to exposed surfaces [8]. These findings were in accordance with the study done by Ellis SD et al. [21] where they found significant reduction in the levels of antioxidants within gingival tissue adjacent to deep periodontal pockets.

A comparison in the GST levels within the gingival tissues and GCF showed no significant changes both in the control and experimental group (Graph I), though it was slightly more evident in the tissues of both the group. The characteristics of the tissue microenvironment could promote elevated concentrations of ROS due to the increased activity of phagocytes [5]. Ceruloplasmin is among the major protease inhibitors, particularly those released by polymorpho nuclear leukocytes (PMN) and might be involved in tissue damage during the course of inflammatory disease [22]. Literature review states that as the degree of gingival inflammation increases, the level of protease inhibitors rises, probably in an attempt to keep up with the increased protease levels within the body [23]. However, the ceruloplasmin levels in GCF and tissues did not show increased levels when compared to the healthy patients. This could be possibly due to the fact the experimental cases selected where chronic periodontitis and since there is a continuous release of proteolytic enzymes during the chronic lesions, the concentrations of these protease inhibitor may not be sufficient to neutralize all proteases [24], resulting in insignificant levels when compared to healthy individuals.

\section{CONCLUSIONS}

Recent years have highlighted considerable attention on ROS and the antioxidant system in the pathogenesis of 
periodontal diseases. Within the limitations of the present study, it was observed that:

1) GST enzyme activity were reduced in both GCF and gingival tissues of diseased individuals

2) In diseased condition, the possibility of high concentration of ROS, may have decreased the antioxidant levels within the body.

However, ceruloplasmin levels did not show any significant changes in both normal and chronic periodontitis. Further clinical studies have to be conducted to evaluate the efficiency of GST as a biomarker that can indicate risk of periodontal tissue loss and need for further proficient intervention.

\section{REFERENCES}

[1] Bissada, N.F., Manouchehr-Pour, M., Haddow, M. and Spagnuolo, P.J. (1982) Neutrophil functional activity in juvenile and adult onset diabetic patients with mild and severe periodontitis. Journal of Periodontal Research, 17, 500-502. doi:10.1111/j.1600-0765.1982.tb02038.x

[2] Pompella, A., Visvikis, A., Paolicchi, A., De Tata, V. and Casini, A.F. (2003) The changing faces of glutathione, a cellular protagonist. Biochemical Pharmacology, 66, 14991503. doi:10.1016/S0006-2952(03)00504-5

[3] Fredriksson, M., Gustafsson A. and Asman, B. (1998) Hyper-reactive peripheral neutrophils in adult periodontitis: Generation of chemiluminescence and intracellular hydrogen peroxide after in-vitro priming and Fc $\gamma \mathrm{R}$ stimulation. Journal of Clinical Periodontology, 25, 394398. doi:10.1111/j.1600-051X.1998.tb02461.X

[4] Kowashi, Y., Jaccard, F. and Cimasoni, G. (1980) Sulcular polymorphonuclear leucocytes and gingival exudate during experimental gingivitis in man. Journal of Periodontal Research, 15, 151-158. doi:10.1111/j.1600-0765.1980.tb00269.x

[5] Gustafsson, A. and Asman, B. (1996) Increased release of free oxygen radicals from peripheral neutrophils in adult periodontitis after Fc $\gamma$-receptor stimulation. Journal of Clinical Periodontology, 23, 38-44. doi:10.1111/j.1600-051X.1996.tb00502.x

[6] Bartold, P.M., Wiebkin, O.W. and Thonard, J.C. (1984) The effect of oxygen-derived free radicals on gingival proteoglycans and hyaluronic acid. Journal of Periodontal Research, 19, 390-400. doi:10.1111/j.1600-0765.1984.tb01012.x

[7] Key, L.L., Wolfe, W.C., Gundberg, C.M. and Ries, W.L. (1994) Superoxide and bone resorption. Bone, 15, 431436. doi:10.1016/8756-3282(94)90821-4

[8] Chapple, I.L.C., Brock, G., Eftimiadi, C. and Matthews, J.B. (2002) Glutathione in gingival crevicular fluid and its relationship to local antioxidant capacity in periodontal health and disease. Molecular Pathology, 55, 367-373. doi: $10.1136 / \mathrm{mp} .55 .6 .367$

[9] Bolt, H.M. and Their, R. (2006) Relevance of the deletion polymorphisms of glutathione-s-transferases in GSTT1 and GSTM1 in pharmacology and toxicology. Current
Drug Metabolism, 7, 613-628.

[10] Miller, E.A., Pankow, J.S., Millikan, R.C., Bray, M.S., Ballantyned, M.C., Bell A.D., Heiss. G. and Li, R. (2003) Glutathione-S-transferase genotypes, smoking and their association with markers of inflammation, hemostatsis and endothelial function: The atheroscelorosis risk in communities. Atheroscelerosis, 171, 265-272. doi:10.1016/j.atherosclerosis.2003.07.007

[11] Goldstein, I.M., Kaplan, H.B., Edelson, H.S. and Weissmann, G. (1982) Ceruloplasmin: An acute phase reactant that scavenges oxygen derived free radicals. Annals of New York Academy of Sciences, 389, 368-379. doi:10.1111/j.1749-6632.1982.tb22150.x

[12] Dutra. F., Ciriolo, M.R., Calabrese, L. and Bechara, E.J. (2005) Amino acetone induces oxidative modification to human plasma ceruloplasmin. Chemical Research in Toxicology, 18, 755-760. doi:10.1021/tx049655u

[13] Blouin, C.C., Page, E.L., Soucy, G.M. and Richard, D.E. (2004) Hypoxic gene activation by lipopolysaccharide in macro-phages: Implication of hypoxia-inducible factor 1alpha. Blood, 103, 1124-1130. doi:10.1182/blood-2003-07-2427

[14] Cramer, T., Yamanishi, Y., Clausen B.E., Forster, I., Pawlinski, R., Mackman, N., Haase, V., Jaenisch R., Corr, M., Nizet, V., Firestein, G.S., Gerber, H.P., Ferrara, N. and Johnson S.R. (2003) HIF-1alpha is essential for myeloid cell-mediated inflammation. Cell, 112, 645-657. doi:10.1016/S0092-8674(03)00154-5

[15] Martin, F., Linden, T., Katschinski, D. M., Oehme, F., Flamme, I., Mukhopadhyay, C. K., Eckhardt, K., Tröger, J., Barth, S., Camenisch, G. and Wenger, R.H. (2005) Copper-dependent activation of hypoxia-inducible factor (HIF)-1: Implications for ceruloplasmin regulation. Blood, 105, 4613-4619. doi:10.1182/blood-2004-10-3980

[16] Beutler, E. (1975) The preparation of red cells for assay. In: Beutler E., Ed., Red Cell Metabolism: A Manual of Biochemical Methods. Grune and Straton Company, New York, 8-18.

[17] Ravan, H.A. (1961) Copper oxidase activity. Journal of Laboratory Clinical Medicine, 58, 161-163.

[18] Chapple, I.L.C. (1997) Reactive oxygen species and antioxidants in inflammatory diseases. Journal of Clinical Periodontology, 24, 287-296. doi:10.1111/j.1600-051X.1997.tb00760.x

[19] Waddington, R.J., Moseley, R. and Embery, G. (2000) Periodontal disease mechanism. Reactive oxygen species: A potential role in the pathogenesis of periodontal disease. Oral Diseases, 6, 138-151. doi:10.1111/j.1601-0825.2000.tb00325.x

[20] Panjamurthy, K., Manoharan, S. and Ramachandran, C.R. (2005) Lipid peroxidation and antioxidants status in patients with periodontitis. Cell Molecular Biology Letter, 10, 255-264.

[21] Ellis, S.D., Tucci, M.A., Serio, F.G. and Johnson, R.B. (1998) Factors for progression of periodontal diseases. Journal of Oral Pathology\& Medicine, 27, 101-105. doi:10.1111/j.1600-0714.1998.tb01923.x

[22] Ohlssen, K. and Ohlssen, I. (1977) Neutral proteases of 
human granulocytes IV. Interaction between human granulocyte collagenase and plasma protease inhibitors. Journal of Laboratory Clinical Medicine, 89, 269-277.

[23] Sandholm, L. and Saxen, L. (1983) Concentrations of serum protease inhibitors and immunoglobulins in juvenile periodontitis. Journal of Periodontonal Research, 18,
527-533.

[24] Ohlssen, K. (1971) Neutral leucocyte proteases and elastase inhibited by plasma alpha-1 antitrypsin. Scandinavian Journal of Clinical Laboratory Investigation, 28, 251-252. doi:10.3109/00365517109095696 